\title{
Endocardial Pacing: A Percutaneous Method Using the Subclavian Vein
}

\author{
C. W. VELLANI*, G. TILDESLEY, AND L. G. DAVIES \\ From the Department of Cardiology, Sully Hospital, Sully, Penarth, Glamorgan
}

Endocardial pacing is an established method of treating complete heart block (Furman, 1967; Lagergren et al., 1966). For long-term pacing the elective site for insertion of the endocardial electrode is usually the external jugular vein, as described by Schwedel, Furman, and Escher (1960). A more recent alternative has been insertion through an antecubital vein, the electrode later being exposed in the axillary vein and attached to an implanted unit in the axilla (Gold, Paneth, and Gibson, 1966). For short-term pacing, a medial vein in the cubital fossa is used, and for rapid insertion percutaneous use of the femoral vein has been described (Soloman and Escher, 1963). In our experience, the tortuous course of the catheter from the external jugular vein can make manipulation into the heart very difficult. Use of the arm is unsatisfactory because the limb has to be immobilized to avoid electrode displacement, this is not always successful, and a further disadvantage is thrombophlebitis at the site of entry at the elbow.

Mobin-Uddin and his associates (1967) have recently described their use of the subclavian vein for short-term pacing. We have practised a similar technique for some years; the electrode is inserted percutaneously and we have found this approach offers considerable advantages for both short-term and long-term use. The technique has been modified over this period and the following account describes our present method.

\section{METHOD}

The procedure is carried out in the cardiac catheterization laboratory. The unsedated patient is placed supine on the screening table, with the head raised on

Received March 27, 1968.

* Present address: Coronary Care Unit, Royal Infirmary, Edinburgh. one pillow and the heart rate controlled with an isoprenaline infusion $(10 \mu \mathrm{g} . / \mathrm{ml}$.$) . Local anaesthetic is$ infiltrated into the skin starting $1 \mathrm{~cm}$. below the midpoint of the clavicle and along the projected needle tract. Through a small stab incision in the skin, a needle obtained from a Bardic "Intracath" set (outer diameter $1.45 \mathrm{~mm}$.) attached to a $2 \mathrm{ml}$. syringe containing 1 per cent lignocaine is directed medially, just deep to the clavicle and along its posterior surface towards the superior aspect of the sternoclavicular joint. The needle is advanced in stages for $3.5-5.0 \mathrm{~cm}$. and lignocaine is injected along its path as required. Entry into the vein is often felt. A $50 \mathrm{~cm}$. Seldinger wire $0.91 \mathrm{~mm}$. in diameter is inserted through the needle and its presence in the superior vena cava confirmed by fluoroscopy. The needle is then replaced by a composite dilator. The dilator consists of a length of white polyethylene tubing (outer diameter $2.6 \mathrm{~mm}$.), one end of which is tapered to the diameter of the guide wire; over this is mounted a shorter length of untapered polythene tubing Portex PP320 (external diameter $3.5 \mathrm{~mm}$.), with one end bevelled so as to provide stepwise dilatation of the needle tract. This is advanced into the vein, and the guide wire and inner polyethylene tube are then removed leaving the outer cannula in situ (Fig. 1). Through this the St. George's " $C$ ", " $D$ ", and the Lucas endocardial electrodes can readily be introduced into the vein and advanced into the right atrium; the cannula is then withdrawn. For insertion of the C50, 51, and 52 (U.S.C.I.) electrodes a length of untapered grey Kifa tubing, one end of which has been rounded, may be inserted over the guide wire after the needle tract has been first dilated with the white polyethylene dilator. The smooth course of the electrode greatly facilitates its manipulation into the right ventricle. Bleeding is slight and readily controlled by gentle pressure over the skin incision.

A satisfactory position having been achieved, the endocardial electrode is fixed to the skin with two silk sutures. An indifferent electrode is then inserted subcutaneously in the opposite pectoral region and pacing established

^ Becton Dickinson \& Co., Rutherford, N.J., U.S.A. † Portland Plastics Ltd., Hythe, Kent. 


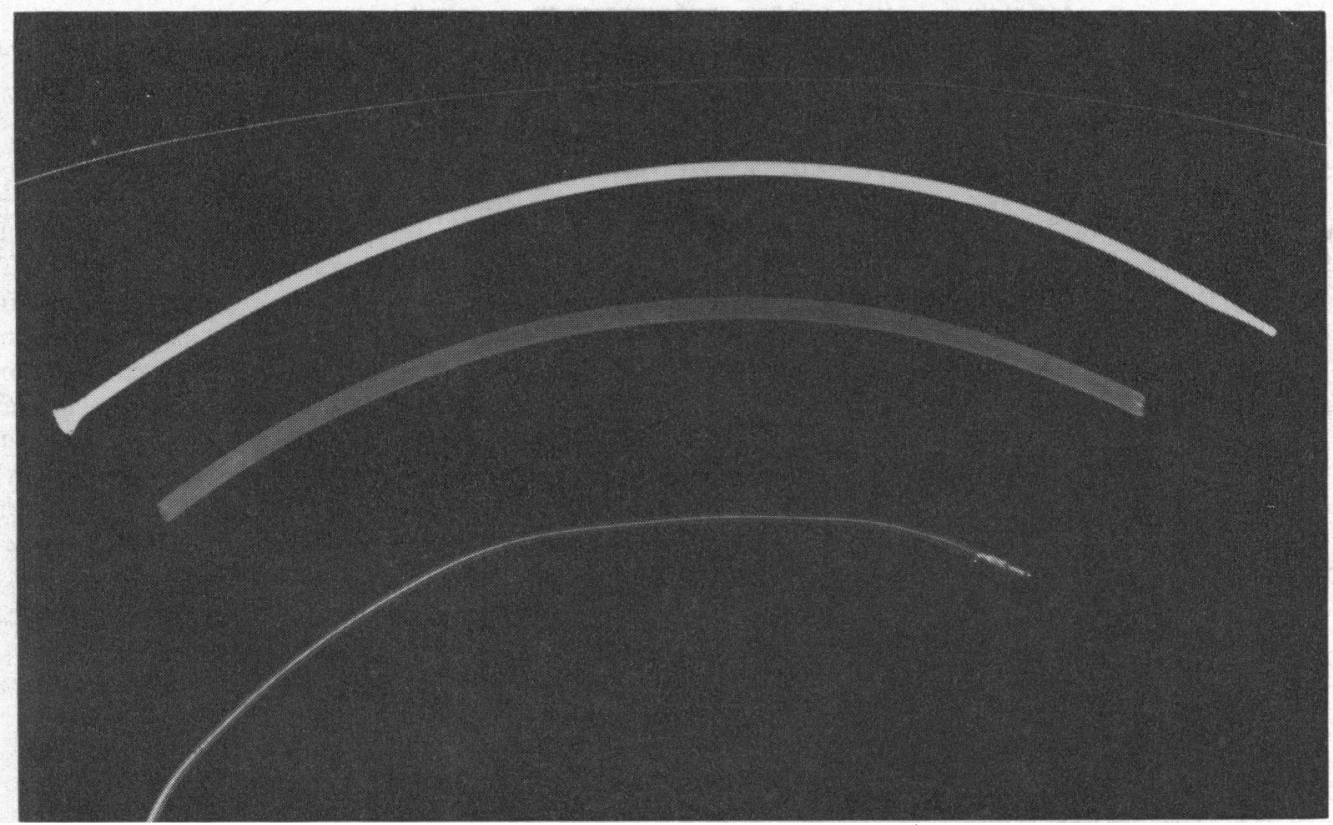

Frg. 1.-From above: $50 \mathrm{~cm}$. Seldinger guide wire, white polyethylene dilator, a shorter length of polythene tubing (Portex PP320) with bevelled end, St. George's "D" type endocardial electrode.

using an external unit made in the department. Routine antibiotic cover is phenethicillin $250 \mathrm{mg}$. six-hourly for 3 days. For short-term pacing as for myocardial infarction with heart block, no further modification has been found necessary and this system has proved satisfactory for periods of up to 5 weeks. In patients requiring long-term pacing, if threshold measurements and catheter position are satisfactory for 1 week, an incision is made at the entry site and a loop of the endocardial electrode fixed firmly to the deep fascia with silk sutures (Fig. 2). With increasing experience, if the catheter position seems entirely satisfactory, this fixation using a subcutaneous loop may be carried out immediately. With the St. George's and Lucas catheters, the loop is reinforced with the sleeve provided and the sutures tied firmly over this. For use with an external unit, the electrode is delivered through a lower skin incision (Fig. 3), and for use with an implanted unit, deep to the péctoralis major through a small incision behind the anterior axillary fold. The incisions are closed after spraying with an aerosol antibiotic. ${ }^{\star}$ After a further 2 weeks, if the electrode position is unchanged and the pacing threshold is satisfactory, an implantable unit can be placed subcutaneously in the axilla under general anaesthesia. The endocardial electrode still attached to the external unit is thoroughly cleansed with surgical spirit and merthiolate, dried, and directly inserted into the implantable unit to which an indifferent electrode has already been attached. The C50 catheters

^ Polymyxin B, Bacitracin and Neomycin Aerosol; Swallowfields Aerosols Ltd., Wellington, Somerset. had to be cut to a suitable length and the insulation removed for about $2 \mathrm{~cm}$. In this way no break in continuity of pacing occurs and the temporary use of a second endocardial electrode is obviated.

\section{RESULTS}

Between August 1964 and May 1968, 55 patients have been paced endocardially by the subclavian approach, 17 of these for periods of up to 5 weeks for the reasons listed in Table $I$, and the remaining. 38 patients for 1 to 40 months (mean 21 months) for chronic complete heart block.

Venepuncture and its Problems. The right subclavian vein is more convenient for right-handed operators and was used initially in 53 patients, the left in only 2 . In many patients the left subclavian has been used subsequently for electrode replacement.

We failed to enter the subclavian vein percutaneously in 4 patients. In 1 patient with kyphoscoliosis, a right-sided attempt resulted in pneumothorax which resolved in 3 days with intercostal tube drainage. This complication did not occur in any other patient. In the second patient, right venepuncture was not successful perhaps because there had been 4 electrode replacements on that side in 22 months. In both these patients the electrode 


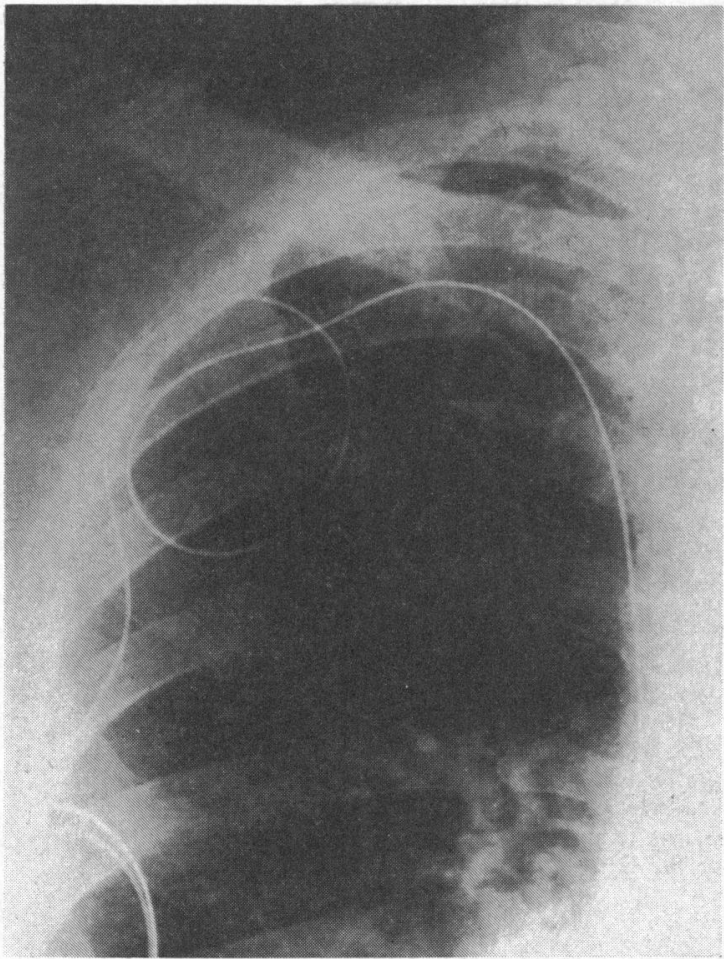

FIG. 2.- $X$-ray showing position of the subcutaneous fixation loop of the endocardial electrode.

was inserted without difficulty into the left subclavian vein. In the third patient left venepuncture failed, the right having contained an electrode for 15 months. The vein was exposed using local anaesthesia and the catheter inserted directly; this approach had to be repeated for replacement 8

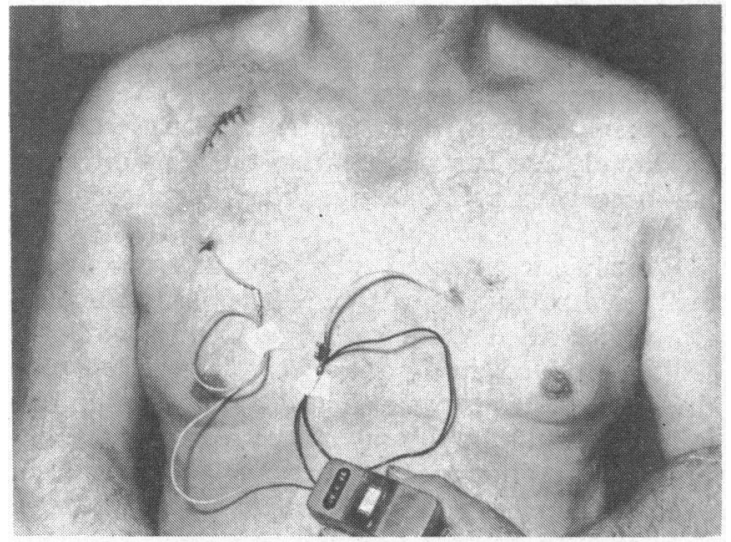

Fig. 3.-Arrangement for pacing with an external unit. months later. The fourth patient presented the same problem: the right subclavian vein had been used for $2 \frac{1}{2}$ years and 3 electrode catheters had been inserted in this period. The fourth attempt at venepuncture was unsuccessful and the vein had to be exposed as above.

In patients where pacing became unsatisfactory, replacement was often possible through the original tract by advancing the appropriate dilator, longitudinally slit so as to invest the electrode, into the vein. Fibrosis can make this difficult and sometimes a lot of force was necessary. In 1 patient, thoracic duct injury was caused while attempting to re-enter the left subclavian vein in this way; there was a chylous discharge which stopped spontaneously after 4 days, and there has been no late complication. We now prefer to replace an electrode catheter through a separate venepuncture on the same or opposite side if dilatation of the original tract is difficult, as it usually is after about 4 weeks.

TABLE I

SHORT-TERM PACING: INDICATIONS AND RESULTS

\begin{tabular}{|c|c|c|}
\hline Indications & No. & Outcome \\
\hline $\begin{array}{l}\text { Myocardial infarction with complete } \\
\text { heart block }\end{array}$ & 14 & 4 deaths \\
\hline $\begin{array}{l}\text { Failed epicardial-abdominal pacing for } \\
\text { chronic heart block }\end{array}$ & 1 & Septicaemic death \\
\hline $\begin{array}{l}\text { Chronic complete heart block with } \\
\text { syncopal attacks }\end{array}$ & 1 & Preferred drugs \\
\hline $\begin{array}{l}\text { Congestive cardiac failure, atrial septal } \\
\text { defect, complete heart block, syncope }\end{array}$ & 1 & $\begin{array}{l}\text { Death unrelated to } \\
\text { pacing }\end{array}$ \\
\hline
\end{tabular}

Electrode Fixation. Repositioning the electrode catheter or replacing it proved necessary for many reasons and these are listed in Table II. Displacement was the major problem with this approach, and early methods of fixation proved unsatisfactory. It has been largely overcome by the present method of loop fixation which has been used for more than 2 years. Thus, only 2 of 43 electrode catheter displacements with external units and 1 of 10 with implanted units occurred after fixation in this way.

Another important cause for replacement was electrode fracture (Table II), and of the 14 instances where this occurred, in 3 the site was the infraclavicular segment. This was after 25,28 , and 32 weeks, respectively, and in 2 patients where fracture occurred in the fixed loop, fixation may have contributed to it. In these 3 patients, C50 (U.S.C.I.) endocardial electrodes had been used; we have not had the same problem with the newer catheters.

Ventricular perforation was suspected on 7 occasions; in each instance a C50 or C52 endocardial electrode had been used and the complication 
TABLE II

REASONS FOR REPOSITIONING OR REPLACING ENDOCARDIAL ELECTRODE

\begin{tabular}{l|r}
\hline & No. \\
\hline Displacement of electrode proximally or into pulmonary & \\
artery: & \\
With external units & 43 \\
With internal units & 10 \\
Ventricular perforation & 7 \\
Rise in threshold & 13 \\
Elective change before unit implant & 11 \\
Fractured C51 electrode & 11 \\
Fractured C50 electrode & 3 \\
Diaphragmatic contractions & 8 \\
Skin sepsis & 2 \\
In error: undetected fault in indifferent electrode & 2 \\
\hline
\end{tabular}

appeared between 2 and 19 days after insertion. The syndrome was characterized by failure of pacing, chest pain, and occasionally pericardial friction. Convincing entry into the pericardium was seen radiographically on only 1 occasion. This complication we believe to be unrelated to the subclavian approach or the method of fixation but to the type of electrode used (Bluestone et al., 1965); it has not occurred with St. George's or Lucas endocardial electrodes. In each instance the electrode was withdrawn without incident, and with this approach repositioning presented no problems.

Infection. All 55 patients were initially paced with an external unit, and of the 38 needing long-term treatment, half have elected to continue with this system. Among patients with external units there have been 12 episodes of local infection around the entry site of the endocardial electrode. In 6 it was associated with collars of yellow Kifa tubing which was an early method of subcutaneous fixation, and twice infection occurred when the stainless steel indifferent electrode was sutured within the loop of the endocardial electrode. No predisposing factors were noted in the remaining 4 episodes. Treatment was with systemic antibiotics, excision of granulation tissue and foreign material, and in 2 patients the endocardial electrode was removed. In no case was there evidence of sepsis involving the subclavian vein.

Nineteen patients elected or were advised to have a St. George's axillary pacemaker implanted. Infection round the electrode in the infraclavicular site occurred in 2 patients and 1 of these died of septicaemia. In a further 2 patients infection appeared around the axillary unit. We have not thought that burying exposed catheter either subcutaneously or in the axilla was likely to carry a serious risk of infection. It is important that the catheter be carefully cleaned as described above, and we now give longer courses of antibiotics after axillary implantation.

Venous Thrombosis. Subclavian vein thrombosis was presumed in one patient who had a small pulmonary infarct 3 days after the third readjustment in catheter position in a fortnight. There was some local tenderness over the left subclavian vein, anticoagulants were given, and the condition resolved. There was no evidence of venous obstruction subsequently or at necropsy 12 months later.

Deaths. Causes of the 13 deaths in this series are listed in Tables I and III; only 4 deaths could be related to pacing and in none was the subclavian approach entirely to blame.

In one patient death was presumed to be due to displacement of an unfixed endocardial electrode attached to an external unit. The other 3 deaths were due to septicaemia. One patient was being paced with an external unit, but septic pericarditis from previous epicardial electrodes was the source of infection, the endocardial electrode, the subclavian vein, and the site of entry all being free from infection and thrombosis. The second patient

^ P. J. Reynolds Ltd., 3 Compton Road, Winchmore Hill London N.21.

TABLE III

LONG-TERM PACING: CAUSES OF DEATH IN 8 PATIENTS

\begin{tabular}{|c|c|c|c|c|c|}
\hline Case No. & Sex & $\begin{array}{l}\text { Age } \\
\text { (yr.) }\end{array}$ & Cause of death & $\begin{array}{c}\text { Duration of } \\
\text { pacing (mth.) }\end{array}$ & $\begin{array}{c}\text { Type } \\
\text { of unit }\end{array}$ \\
\hline 1 & $\mathbf{F}$ & 66 & Septicaemia & \multirow{6}{*}{$\begin{array}{c}\left\{\begin{array}{c}6 \\
2 \frac{1}{2} \\
14 \\
7 \\
17 \\
1 \frac{1}{2} \\
7\end{array}\right. \\
\left\{\begin{array}{r}14 \\
9 \\
10 \\
2 \\
40\end{array}\right.\end{array}$} & \multirow{6}{*}{$\begin{array}{l}\text { External } \\
\text { Internal } \\
\text { External } \\
\text { Internal } \\
\text { External } \\
\text { Internal } \\
\text { Internal } \\
\text { External } \\
\text { External } \\
\text { Internal } \\
\text { External } \\
\text { External }\end{array}$} \\
\hline 2 & $\mathbf{M}$ & 66 & Septicaemia & & \\
\hline 3 & $\mathbf{F}$ & 73 & Myocardial infarction & & \\
\hline $\begin{array}{l}4 \\
5\end{array}$ & $\begin{array}{l}\mathbf{M} \\
\mathbf{M}\end{array}$ & $\begin{array}{l}74 \\
58\end{array}$ & $\begin{array}{l}\text { Myocardial infarction presumed } \\
\text { Cerebral thrombosis }\end{array}$ & & \\
\hline 6 & $\mathbf{M}$ & 69 & Cause unknown & & \\
\hline $\begin{array}{l}7 \\
8\end{array}$ & $\underset{\mathbf{F}}{\mathbf{M}}$ & $\begin{array}{l}68 \\
73\end{array}$ & $\begin{array}{l}\text { Catheter displacement } \\
\text { Cerebral thrombosis }\end{array}$ & & \\
\hline
\end{tabular}


had been paced with an external unit for 6 months. There had been several episodes of displacement, and she was admitted with infection at the catheter entry site. Shortly afterwards pacing failed and the catheter was repositioned. She was advised to have an axillary unit and after the infection appeared to have completely resolved the catheter was fixed and the unit implanted. Death from septicaemia occurred 11 weeks later. The subclavian vein and axillary pocket were free from infection, but there was a little pus around the infraclavicular fixation loop, and this was the probable source of her septicaemia.

The third septicaemic death occurred in a patient who had been paced with an implanted unit for 14 weeks; the unit and the electrode were exteriorized because of axillary infection; skin infection around the endocardial electrode and displacement followed. Ampicillin was given and the electrode was repositioned. Its insulation was noted to be fractured and 1 week later a fresh electrode was inserted from the opposite side. Death occurred 3 weeks later in left ventricular failure. At necropsy, vegetation adherent to both electrodes grew Staphylococcus aureus, and there was moderate splenomegaly; coronary artery disease was severe, with old myocardial infarction, but no fresh change was noted. There was no evidence of infection or thrombosis in the subclavian veins.

\section{Discussion}

Subclavian venepuncture has been advocated for measurement of central venous pressure in shock states, prolonged infusion of fluid, hypertonic solutions, irritant drugs, and repeated catheterization of the right heart and pulmonary arteries (Wilson, 1963; Davidson, Ben-Hur, and Nathen, 1963; Gulde et al., 1965). Advantages of the constant site (Keeri-Szanto, 1956) of a large immobile vein which can retain a cannula for a long time and which is readily accessible percutaneously suggest that the subclavian vein is an ideal site for insertion of an endocardial pacing electrode.

Schwedel et al. (1960) used the external jugular vein for insertion of the pacing electrode because it allowed mobility of the upper limbs, relative ease of positioning the electrode from this site, with the additional advantages of its relatively large size, accessibility, and constant position.

Like ourselves, others have frequently had great difficulty in advancing the electrode from the external jugular vein into the heart because of its tortuous route. Gordon (1965) failed to guide the electrode into the heart from the right external jugular vein in 15 patients-though it was successful in 39 , in 5 others no suitable right external jugular vein could be found. When manipulation of the electrode was difficult the lower course of the external jugular below the clavicle was dissected out (Bluestone et al., 1965), or open insertion into the internal jugular vein was effected. Anomalies of the external jugular veins have been noted by Paulk and Hurst (1966).

The external jugular vein needs to be preserved for elective endocardial pacing and does not lend itself to repeated use so that interim pacing from an upper limb vein is necessary. Likewise, for emergency pacing an antecubital vein is frequently used, and percutaneous insertion into the femoral vein has been recommended for short periods (Soloman and Escher, 1963). Both these insertions suffer from the disadvantage of the need to immobilize the appropriate limb to prevent dislodgement of the electrode.

Our percutaneous technique offers repeated use of the subclavian veins and ease of manipulation of the pacing electrode. It can, therefore, be used for urgent or elective endocardial pacing. In addition, it does not interfere with neck or upper limb movements, subcutaneous fixation is easier to perform in the pectoral region than in the neck, stability now seems satisfactory, and from its infraclavicular position the catheter may be easily transferred to an implanted unit in the axilla, pectoral region, or the abdominal wall. We have not encountered an unduly high incidence of infection around the implanted pacemaker and electrode in the axilla; this suggests that the method of implanting an endocardial electrode which has been attached to an external pacemaker does not expose the patient to an unnecessary risk. Thus, the necessity for a second temporary endocardial electrode does not arise and positional adjustments can be undertaken before its fixation and connexion to an implanted unit 2 weeks later.

Much has been written about the complications of subclavian venepuncture (Lancet, 1963; Matz, 1965), and because of these, percutaneous puncture of the axillary vein has been advocated instead (Spracklen et al., 1967). In our series 1 puncture out of 80 resulted in pneumothorax and was due to distortion of the anatomy by upper dorsal kyphoscoliosis; nevertheless, it was possible to use the vein on the opposite side. Haemorrhage, haematoma, and air embolism have not occurred. The thoracic duct was injured in one patient as the result of dilatation of a fibrous tract into the left subclavian vein but was not produced by venepuncture. Phlebothrombosis may have occurred in one patient with pulmonary infarction after repeated manipulation of the electrode over 12 days, but no venous occlu- 
sion resulted nor was there evidence of thrombosis at necropsy 12 months later.

Venepuncture has presented comparatively few problems. Failure to enter the vein in one patient was due to its small size, as shown at the time of open insertion; in 2 others it was due to fibrosis resulting from 4 electrode insertions during 2 years of continuous use. But in general even repeated use has not been difficult and has not produced damage to the vein.

Skin sepsis around the endocardial electrode in those paced with external units occurred without predisposing cause in 4 patients. It was effectively treated with systemic antibiotics and did not recur. Septicaemia from this cause is a potential hazard and a long subcutaneous tract has been recommended (Gotsman et al., 1966). In our patients exit from the skin was approximately $10 \mathrm{~cm}$. from the vein with an intervening loop; despite this short course septicaemia related to skin infection occurred in only 2 patients in circumstances that were avoidable.

Bacterial endocarditis, other than of the tricuspid valve in one patient who died of septicaemia, has not occurred, but only 2 patients of the series had abnormal valves.

\section{SUMMARY}

Since August 1964, 55 patients with heart block have been paced by means of an endocardial electrode introduced percutaneously into a subclavian vein and an external unit.

Seventeen patients required short-term pacing for periods of up to 5 weeks, 14 of them for heart block complicating acute myocardial infarction.

The 38 patients with chronic block have been paced for a mean period of 21 months, 19 being changed to an internal unit after observation for several weeks had confirmed satisfactory electrode position and threshold. The remainder have continued with an external unit.

We have found that the subclavian vein has many advantages over the jugular and limb veins. Ready accessibility of the vein, ease of manipulation of the electrode into the heart, and the facility of repeated puncture for its replacement are particularly useful for emergency as well as long-term pacing.
The risks of subclavian venepuncture have been greatly exaggerated; we have found it to be a safe procedure if the technique is followed closely and there is no great distortion of the anatomy.

\section{REFERENCES}

Bluestone, R., Davis, G., Harris, A., Leatham, A., and Siddons, H. (1965). Long-term endocardial pacing for heart-block. Lancet, 2, 307.

Davidson, J. T., Ben-Hur, N., and Nathen, H. (1963). Subclavian venepuncture. Lancet, 2, 1139.

Furman, S. (1967). Fundamentals of cardiac pacing. Amer. Heart f., 73, 261.

Gold, R. G., Paneth, M., and Gibson, R. V. (1966). A new technique for long-term endocardial pacing. Lancet, $1,908$.

Gordon, A. J. (1965). Catheter pacing in complete heart block. Techniques and complications. f. Amer. med. f., 193, 1091.

Gotsman, M. S., Beck, W., Piller, L. W., Bosman, S. C. W., Barnard, C. N., and Schrire, V. (1966). Modified technique for long-term endocardial pacemaking. Brit. med. f., 2, 1357.

Gulde, R. E., Malinak, L. R., McMullen, F. F., Turell, D. J., and Hanson, H. H. (1965). Percutaneous subclavian catheterization of the right heart and pulmonary arteries. Amer. Heart F., 70, 481.

Keeri-Szanto, M. (1956). The subclavian vein, a constant and convenient intravenous injection site. Arch. Surg., 72, 179.

Lagergren, H., Johansson, L., Schüller, A., Kugelberg, J., Bojs, G., Alestig, K., Linder, E., Borst, H. G., Schaudig, A., Giebel, O., Harms, H., Rodewald, G., and Scheppokat, K. D. (1966). 305 cases of permanent intravenous pacemaker treatment for Adams-Stokes syndrome. Surgery, 59, 494.

Lancet (1963). Subclavian venepuncture. 2, 1152.

Matz, R. (1965). Complications of determining the central venous pressure. New Engl. f. Med., 273, 703.

Mobin-Uddin, K., Smith, P. E., Lombardo, C., and Jude, J. (1967). Percutaneous intracardiac pacing through the subclavian vein. F. thorac. cardiovasc. Surg., 54, 545.

Paulk, E. A., Jr., and Hurst, J. W. (1966). Complete heart block in acute myocardial infarction. A clinical evaluation of the intracardiac bipolar catheter pacemaker. Amer. F. Cardiol., 17, 695.

Schwedel, J. B., Furman, S., and Escher, D. J. W. (1960). Use of an intracardiac pacemaker in the treatment of Stokes-Adams seizures. Progr. cardiovasc. Dis., 3, 170.

Soloman, N., and Escher, D. J. W. (1963). A rapid method for insertion of the pacemaker catheter electrode. Amer. Heart F., 66, 717.

Spracklen, F. H. N., Niesche, F., Lord, P. W., and Besterman, E. M. M. (1967). Percutaneous catheterization of the axillary vein. Cardiovasc. Res., 1, 297.

Wilson, J. N. (1963). The management of acute circulatory failure. Surg. Clin. N. Amer., 43, 469. 